\title{
Regulation as Delegation
}

\section{Citation}

Oren Bar-Gill \& Cass R. Sunstein, Regulation as Delegation (February 25, 2015).

\section{Published Version}

http://ssrn.com/abstract=2570669

\section{Permanent link}

http://nrs.harvard.edu/urn-3:HUL.InstRepos:15858414

\section{Terms of Use}

This article was downloaded from Harvard University's DASH repository, and is made available under the terms and conditions applicable to Open Access Policy Articles, as set forth at http:// nrs.harvard.edu/urn-3:HUL.InstRepos:dash.current.terms-of-use\#OAP

\section{Share Your Story}

The Harvard community has made this article openly available.

Please share how this access benefits you. Submit a story.

\section{Accessibility}




\title{
Regulation As Delegation
}

\author{
Oren Bar-Gill ${ }^{*}$ and Cass R. Sunstein ${ }^{* *}$
}

1525 Massachusetts Ave.

Cambridge, MA 02138

Phone: 617-495-4623

Email: bargill@law.harvard.edu 


\begin{abstract}
In diverse areas - from retirement savings, to fuel economy, to prescription drugs, to consumer credit, to food and beverage consumption - government makes personal decisions for us or helps us make what it sees as better decisions. In other words, government serves as our agent. Understood in light of Principal-Agent Theory (PAT) and Behavioral Principal-Agent Theory (BPAT), a great deal of modern regulation can be helpfully evaluated as a hypothetical delegation. Shifting from personal decisions to public goods problems, we introduce the idea of reverse delegation, with the government as principal and the individuals as agents.
\end{abstract}


In diverse areas - from retirement savings, to consumer credit, to prescription drug use, to fuel economy and energy efficiency rules, to tobacco consumption, to food and beverage consumption - government makes decisions for us or endeavors to help us make better decisions. In other words, government serves as our agent. Principal-Agent Theory (PAT), broadly applied in economics and political science, can serve as a useful framework for considering the optimal scope and nature of this assistance that our agent, the government, provides.

It is quite common to talk about government as the agent of the People in a democratic society (Ackerman 1993). ${ }^{1}$ Our focus is not on the People, but rather on an individual person. Accordingly, we are thinking about personal decisions - decisions whose primary effect is on a single principal, an individual. ${ }^{2}$ To this extent, we are excluding cases in which people's decisions affect others. This is not to say that these personal decisions do not have external effects. Often they do. When people eat unhealthy food, they might affect others as well, especially if they become sick. Whenever nations have welfare systems, making sure that people are healthy, save enough, and borrow prudently may prevent third-party effects. ${ }^{3}$ But our focus in this Article is on the well-being of the individual, seen as principal.

Our central claim here is that read in light of PAT, a great deal of modern regulation can be understood and evaluated as a hypothetical delegation, through which sensible principals delegate authority to those who can make decisions on their behalf. This claim 
helps cast a fresh light on some objections to apparent paternalism - as, for example, where government requires people to obtain a prescription before using certain medicines, or forbids workers from running certain risks in the workplace. The use of PAT helps to discipline discussions that might otherwise be far too abstract. Adding a behavioral lens, Behavioral PAT (BPAT) helpfully enriches the basic analysis, suggesting that boundedly rational principals will be prone to both insufficient and excessive delegation. ${ }^{4}$

One of our principal goals is to enlist PAT and BPAT to distinguish among several distinctive kinds of hypothetical delegations, involving information, default rules, incentives, precommitments, mandates, and prohibitions. Focusing on the benefits and costs of delegation, which depend on its type, we identify the circumstances in which one or another approach makes sense.

In the domain of personal decisions, we argue, it is helpful to think about the individual as principal and the government as agent. A different set of regulatory problems - public goods problems - can be conceptualized as a reverse delegation, with the government as principal and the individuals as agents. Here the government-principal, as representative of the People, sets a public objective - a clean, sustainable environment, financial stability, higher educational attainment - and enlists individuals-agents to help attain this objective. 
Our central argument is that the idea of regulation-as-delegation provides a useful frame for the evaluation and design of regulation. It brings to the fore personal decisions as a central object of regulation. It offers a unified model for studying disparate regulatory tools that are usually considered in isolation, highlighting important interactions between them. It captures both hypothetical and actual judgments and decisions by informed but boundedly rational agents, who often favor delegations of this kind (Sunstein 2015a, Sunstein 2015b, Bar-Gill and Sunstein 2015). It embeds this unified model of regulatory powers in an even more general framework that exposes the necessary links between the design of regulatory agencies - their structure, goals, and incentives - and the powers afforded to these agencies.

We acknowledge that a sophisticated analysis of welfare-maximizing regulation could produce many (all?) of the results that we describe, without recourse to the delegation frame. It would be possible to dispense with that frame and simply to ask: What kinds of regulation actually promote social welfare? We view regulation-as-delegation not as a substitute for welfare analysis, but rather as a vehicle for pushing welfare analysis further and deeper, and for identifying features of the analysis that might otherwise be ignored. And independent of the direct welfare question, it is valuable to ask about the kinds of delegations that people would, and do, support. We approach that question theoretically, by trying to specify when and why such support would be forthcoming. In ongoing work, we test the theory against survey evidence (Bar-Gill and Sunstein 2015; see also Sunstein 2015a, Sunstein 2015b). 
In particular, PAT and BPAT help to identify more clearly the proper scope of regulation. Focusing on personal decisions, the delegation frame emphasizes deficits of information and of rationality on the part of regulated individuals as the main reason for regulatory intervention. ${ }^{5}$ PAT and BPAT also help to identify and design the appropriate regulatory approach. For example, we conceptualize default rules as veto-based delegation - as a course of action that the government-agent suggests to the individual-principal. We show that the desirability of this regulatory approach depends on the alignment (or misalignment) of interests between the principal and the agent and on the ability of the individual-principal to effectively exercise her veto power, i.e., to opt-out of the default when it is appropriate to do so.

The unified regulation-as-delegation framework also highlights important interactions between different regulatory tools. In the literature, disclosure mandates and default rules are usually discussed separately. We argue that often, they are best understood as complements: default rules will not work well unless individuals have sufficient information effectively to exercise their veto-power and choose whether to opt-out of the default. Sometimes, of course, individuals will already have that information, or the market will generate it, but sometimes disclosure is desirable or necessary to make optout rights something more than a formality. Finally, as a normative matter, conceptualizing regulation as delegation, in the personal decisions domain, bolsters the legitimacy of some regulation, which might otherwise seem questionable as a form of 
paternalism - but only when the relevant regulation conforms to the optimal delegation contract. $^{6}$

Another contribution of this Article is in employing the regulation-as-delegation frame as a bridge between two important literatures that have developed independently, yet have much to learn from each other. On the one hand, the behavioral economics literature studies policy interventions that respond to the bounded rationality of individuals, but sometimes without fully considering the ignorance, the motivations, or the misalignment of interests of regulators. On the other hand, the political science and administrative law literature pays much attention to regulatory agency costs, but much less attention to the bounded rationality of individuals and how it affects the optimal scope of regulation. Standard treatments of "market failures" do not devote much discussion to the kinds of "behavioral market failures" that, in our view, provide the strongest justification for prominent regulatory regimes.

The Article proceeds as follows. Part I develops the general PAT and BPAT model of regulation in the domain of personal decisions. Part II characterizes different regulatory tools according to the degree of implied delegation; highlights novel interactions between different forms of regulation-as-delegation; and identifies the factors that regulators should consider as they strive for optimal delegation. Part III applies PAT and BPAT to public goods problems, where regulation can be usefully analyzed as a reverse delegation. 


\section{Delegating Personal Decisions}

\section{A. Hypothetical Delegation}

To be clear, we are not thinking about an actual, affirmative act of delegation between an individual principal and a government agent. Such express delegation, which is the standard assumption in PAT as applied in economics (Fama 1980; Holmstrom \& Milgrom 1991), is unrealistic in the regulatory context, because individual citizens lack the authority to make such delegations. ${ }^{7}$ Rather our focus is on hypothetical delegation, designed to illuminate the normative questions. ${ }^{8}$ In our view, an understanding of hypothetical decisions helps to illuminate the structure of well-functioning regulatory systems, which may arise from an actual, and emphatically nonhypothetical, demand from many or most citizens. In the context of food and drug safety, for example, or to prevent train and airplane accidents, the public seems to demand some kinds of regulatory safeguards, effectively delegating authority. But when, and of what kind? For simplicity, consider a sophisticated individual who does not have the time or knowledge to make an optimal decision on her own (or does not have the time to acquire the requisite knowledge). Would this individual want to delegate the decision to a government agent - either fully or partially? 
It is useful to divide this question into two sub-questions: First, would the individual want to delegate the decision to an agent? Second, would the individual prefer a government agent or a private agent? The PAT model of regulation focuses on situations where (1) delegation is beneficial and (2) government is a good agent. The condition that government is a good agent is intended to cover scenarios where a government agent is better than a private agent. It is also intended to cover the common scenario, where a private agent is better than a government agent, but transaction costs or other market failures make it too expensive for (at least some) individuals to delegate to a private agent. $^{9}$

To see the case for regulation as delegation, consider a sophisticated principal who would want to delegate a decision to a government agent. Regulation that implements such a delegation can thus be viewed as tracking the principal's informed preferences. To that end, the regulation should be designed to mimic the delegation contract that the principal would write. One question is whether the principal finds it a benefit or a cost actually to make decisions. It is true and important that some principals very much want to make some decisions on their own (Fehr, Herz, \& Wilkening 2013) - perhaps because they enjoy doing so, perhaps because they trust their own judgment in certain domains, perhaps because they want to exercise agency or take responsibility - and would build that restriction into the contract. And as we shall see, certain kinds of regulation have restrictions of that kind; consider information disclosure, which (unlike a default rule) not only preserves the principal's ultimate authority to choose but also calls for an active 
choice on the part of the principal. But some principals do not enjoy making certain decisions, and others want to avoid responsibility and much prefer a situation in which that responsibility lies with someone else. (These points have analogies in cases in which Congress grants, or delegates, broad discretionary authority to the executive branch.) As we shall also see, certain kinds of regulations constrain the principal's ultimate authority for reasons of this kind.

In reality, many individuals are less than sophisticated or poorly informed. These individuals may or may not appreciate the benefit from delegation. ${ }^{10}$ If they are aware of their own informational deficits, they might be especially appreciative; but this cannot be guaranteed. They might resent and reject a delegation that they would embrace if they were informed. Again, regulation-as-delegation can be conceptualized as the arrangement that the individuals would have chosen had they been sophisticated and well-informed. As we will see below, the optimal regulatory structure - the optimal design of the hypothetical delegation contract - depends in part on our beliefs about the sophistication of the individuals-principals and the information they are thought to possess, as well as their own vulnerability to behavioral biases (and also the corresponding vulnerability of their agents).

It is important to recognize that, as compared to actual delegation, hypothetical delegation provides a weaker normative basis for regulation (or anything else). It is one thing to point to actual consent; it is quite another to hypothesize it. ${ }^{11}$ If delegation is not 
actual, its use is less clearly correct as a legitimating device. More generally, the idea of hypothetical delegation raises distinctive issues and concerns.

In contract law and corporate law, legal defaults track the hypothetical contract, or hypothetical corporate structure, that a majority of contracting parties, or a majority of corporate shareholders, would want (Ayres 1998; Ayres \& Gertner 1989; Easterbrook \& Fischel 1989, 1417). The normative basis for these hypothetical contracts and structures rests in their likely connection with parties' desires and in the ability of the parties to optout and design their own contracts and structures. The effort to track majority will and the ability to opt-out brings us closer to actual assent, bolstering the legitimacy of the default rule. In the regulatory context, there is an analogy, but it is not perfect. As in contract law and corporate law, the delegation should track people's likely desires. And, as we shall see, the delegation might take a limited form, allowing opt-out by individuals who do not like the presumed approach.

When there is a certain delegation in place, e.g., a ban on a certain (dangerous) product, representing a delegation of product choice to the government-agent, opt-out is not possible for individuals, but it may occur at the collective level. Consumers, employees, or borrowers who prefer less delegation, or no delegation, can lobby the government and push for the desired adjustment. To be sure, political economy constraints limit the viability of such opt-out in many cases (Warren \& Wood 2014; Bubb \& Warren; Gayer \& Viscusi 2015). But even in contract law and corporate law, transaction costs, agency 
costs, and asymmetric information limit the strength of the opt-out argument (Bebchuk 1992; Bar-Gill \& Bebchuk 2006; Ayres \& Gertner 1989; Bebchuk \& Shavell 1991). While our thesis must rest on the narrower foundations of hypothetical delegation, there are cases where we come closer to actual delegation.

In a companion piece, we offer survey evidence suggesting that, in many cases, individuals would like to delegate to a government agent (Bar-Gill and Sunstein 2015; see also Sunstein 2015a). While this evidence does not demonstrate actual delegation, it does bolster the normative case for regulation.

B. The Benefits and Costs of Delegation

1. Why Delegate? The Benefits of Delegation

If delegation is to serve as a useful lens for evaluating and designing regulation, we must first understand the reasons for delegation. Why would an individual want to delegate a decision to a government-agent?

Principals delegate decisions to agents (1) because they do not have time to make all the required decisions on their own, (2) because they do not enjoy making those decisions, (3) because they do not want to take responsibility, (4) because the agent is better 
informed or enjoys greater expertise, or (5) because the agent is otherwise more likely to make good choices (for example, because he is calmer, less subject to behavioral biases, or more objective). In other words, a delegation can reduce the costs of decisions, the costs of errors, or both. To make the idea vivid, imagine an agent who would be able to make precisely the decisions one would oneself make, if one had time and information, and if one were free from relevant biases. Unless choice-making were believed to be valuable in itself - and it sometimes is (Fehr, Herz, \& Wilkening 2013), as we shall see the act of delegation would, under those circumstances, be highly attractive.

For a concrete example, think of a corporate board delegating to the company's management team. The board cannot possibly make all the decisions required for the dayto-day operation of the company. Or consider the CEO of a large company. She cannot possibly make all necessary decisions about each employee, about each feature of the company's numerous products or services, and about the relationship between the company and each of its millions of customers. Indeed, management experts and markets are critical of CEOs who attempt to micromanage and in that sense fail to delegate (Weyand 1996).

Even if a principal is as good as an agent, or indeed even if a principal is better than an agent, delegation has significant advantages simply because it saves time and thus eliminates a kind of "bandwidth tax." ${ }^{\text {"12 }}$ The CEO of a company, or indeed the president of the United States, might believe himself to be the best decision-maker across a broad 
territory but might delegate simply in order to avoid being overwhelmed by the sheer number of decisions. Consider these words from President Barack Obama: "You'll see I wear only gray or blue suits. I'm trying to pare down decisions. I don't want to make decisions about what I'm eating or wearing. Because I have too many other decisions to make." (Lewis 2012). Even in its standard form, PAT has not paid enough attention to the bandwidth problem, which is sufficient to justify a large number of delegations.

In the context of personal decisions, the same point holds. If individuals had to make decisions about everything that affects their lives, they would quickly be overwhelmed (Conly 2012). Within families, explicit or implicit delegations occur every day, and when things are working well, they are designed to produce a productive division of labor. Government itself, and delegations to public officials, greatly simplify life insofar as they make it unnecessary for individuals to acquire information and to make decisions of various sorts - a point to which we will return.

An additional benefit of delegation follows when the agent has superior information and expertise. ${ }^{13}$ Indeed, the principal may want to delegate to the agent the task of acquiring information and expertise in a certain area. Since the principal needs to make many decisions across many different contexts, she will benefit from delegating these information-gathering tasks to different agents. For example, I may want to delegate to the Consumer Finance Protection Bureau (CFPB) the task of gathering information and acquiring expertise in the financial context. At the same time, I may want to delegate to 
the Food and Drug Administration (FDA) the task of gathering information and acquiring expertise about nutrition and pharmaceutical products. I do not want to take medicines that do not work, or that make me sicker, and hence I delegate to the FDA the authority to make rules governing prescription drugs. ${ }^{14}$

Bounded rationality, including an assortment of behavioral biases, provides additional reasons to delegate. BPAT emphasizes that boundedly rational principals should delegate, because they can avoid biased decisions by delegating to unbiased, fully rational agents. Suppose, for example, that some principals suffer from optimistic bias or present bias, or that they would display the endowment effect, perhaps to their detriment. If so, they might want to delegate authority to someone who would not show the relevant biases. Indeed, there is evidence that people do not display the endowment effect when they are acting as agents - a strong point in favor of using agents (Arlen, Spitzer, \& Talley 2002; Arlen \& Tontrup 2015). There is also evidence that when people are acting as agents for others, they do not show optimistic bias, another strong point in favor of using agents (Pronin 2002; Sharot 2011). If people use heuristics that produce serious errors, they might well favor some kind of delegation. ${ }^{15}$

With respect to personal decisions, the constraints of time and information often loom large, even for fully rational choosers. Most individuals would want to, and find time to, participate in decisions affecting their retirement savings, their mortgage financing, their credit card borrowing, and the food they consume. But often they lack the necessary 
information or expertise to make an optimal decision on their own. And often they lack the time and interest to acquire the necessary information or expertise. ${ }^{16}$ Delegation to a better-informed, expert agent would thus be an attractive option - at least if the experts' motivations can be trusted.

Moreover, these personal decisions are frequently affected by bias, misperception and other forms of imperfect rationality. Procrastination might result in insufficient saving for retirement (Laibson 2015). Optimism and myopia might lead to excessive borrowing (Bar-Gill 2012). Affect-driven food choices might result in adverse health consequences (Canetti, Bachar, \& Berry 2002; Wansink 2014). A sophisticated individual who is aware of her imperfect rationality would seek to avoid a biased decision by delegating to an unbiased agent. And to protect naïve individuals who are unaware of their imperfect rationality, it may be desirable to impose such delegation. ${ }^{17}$

It is essential to emphasize that the benefits of delegation depend on the information, expertise, and motivations of the agent (Glaeser 2006; Gigerenzer 2015a). On standard Hayekian grounds, we might think that government will lack important information about the preferences, values, and tastes of individuals (Hayek 2014). If so, there will be an argument for a limited delegation or for no delegation. Arguing in favor of his famous Harm Principle, Mill emphasized the same problem. In Mill's view, the problem with outsiders, including government officials, is that they lack the necessary information. Mill insists that the individual "is the person most interested in his own well-being," and 
the "ordinary man or woman has means of knowledge immeasurably surpassing those that can be possessed by any one else." (Mill 1859) When government seeks to help with our personal decisions, it does so on the basis of "general presumptions," and these "may be altogether wrong, and even if right, are as likely as not to be misapplied to individual cases." (id.)

In our view, these claims are too stark. In many areas, outsiders, including government, have epistemic advantages over choosers. An understanding of behavioral biases suggests that Mill's emphasis on the knowledge of the "ordinary man or woman" is far too optimistic. (For evidence in an important context, see Bhargava, Loewenstein and Sydnor 2015.) But it is true that when the potential government agent has more limited advantages, in terms of information and expertise, there is less reason to delegate. This point is especially important when the agent has particular values and tastes, which the government agent may not understand or appreciate. And when the potential agent might suffer herself from cognitive bias, or other forms of imperfect rationality, there is less reason to delegate to that agent. It should go without saying that if the agent has motivations of her own, diverging from those of the principal, then a delegation is far less attractive. The emerging field of "behavioral public choice" (Schnellenbach \& Schubert 2015; Gayer \& Viscusi 2015) rightly emphasizes points of this kind, and they can easily be made part of BPAT.

\section{The Costs of Delegation}


Delegation can have important benefits, but as the immediately preceding discussion suggests, it can also impose serious costs. Standard PAT emphasizes the risks (to the principal) from delegation. When the interests of the agent are not perfectly aligned with the interests of the principal, delegation can be harmful to the principal. In particular, the better-informed agent might make decisions that promote her own interests, rather than those of the principal. ${ }^{18}$ In the catchphrase, information is power. (Compare: Aghion \& Tirole 1997, 21) Delegation seeks to harness this power by employing a better-informed agent. But the power of information can be turned against the principal, when the interests of the principal and the agent are misaligned. If the public officials are taken as the agents, their own motivations, or those of powerful private groups to which they are beholden, might produce a serious misalignment.

The related problem of "moral hazard" has been studied in many contexts that involve PAT. ${ }^{19}$ An employee might shirk on the job, if her effort level is unobservable by her employer. A manager might choose an excessively risky project (or an excessively safe project), if relevant features of the project are unobservable to shareholders. And the Administrator of the EPA is more likely to take action - regulatory action or enforcement action - not in line with the President's policy preferences, if this action is unobservable to the President (Yellen 1984; Hermalin 1993; Bubb \& Warren 2014). These risks are, in some sense, inherent to delegation. As Arrow succinctly explains: "by definition the agent has been selected for his specialized knowledge and the principal can never hope to 
completely check the agent's performance." (Arrow 1964)

Delegation of personal decisions to a government agent entails similar risks and costs. An agent who believes deeply in the importance of healthy eating may promote food consumption choices that do not reflect the preferences of an individual-principal who greatly enjoys a particular unhealthy food (Rebonato 2011). The agent might also promote the interests of particular providers - say, the dairy or meat industry - at the expense of those of the individual-principal. Similarly, the level of saving or borrowing that the agent deems appropriate might deviate from what the individual-principal would have chosen, had she been perfectly informed and perfectly rational (Zywicki 2012).

As we have seen, one source of the problem is misalignment of interests. There are several possible sources for such misalignment. The first is pure paternalism: the government agent believes that she knows what is best for the principals, even if the relevant principals do not see it that way. ${ }^{20}$ In the cases we have in mind, the government is second-guessing people's ends (rather than their means), and pushing them toward choices that they would reject, even if they were perfectly informed and unbiased. You should be discouraged from buying chocolate candy, even if you really enjoy chocolate candy and believe that the health risks are worth incurring. You should save more for retirement, even if you (rationally) believe that you have a really pressing current consumption need, which outweighs the value of additional savings (now). 
A second and related problem occurs when the agent is imperfectly informed about the individual-principal's preferences. Here the government agent does not want to impose her paternalistic preferences; she strives to follow and implement the preferences of the individual-principal, but her information about those preferences is limited. For example, and consistent with Mill's central concern, the agent may promote a savings level that is beneficial for the average person, but not for a specific individual with specific preferences or needs. ${ }^{21}$ Or the agent might believe that a particular principal wants to stop smoking when nothing could be further from the truth. Consider here the fact that when buying presents during holiday season, family members and friends make systematic and costly errors about the preferences of the recipients, causing billions of dollars in deadweight losses (Waldfogel 2009). If family members and friends make such errors, government agents will often be unreliable, simply because they lack important information.

The third source of misalignment is capture. In contrast to the well-meaning paternalistic agent, or the misinformed one, the captured agent is promoting the interests of some third party, the food industry or the financial sector, for example, at the expense of the individual-principal. You should drink milk and eat beef, because that is in the best interest of powerful dairy and beef producers. You should be encouraged to obtain risky credit card or mortgage products, because the banking industry stands to gain. A related form of indirect capture occurs when a regulator had a previous career in the industry or foresees a future career in the industry; there may be a risk that experience, or future 
career prospects, will create capture. In the crudest form, the agent is genuinely focused on the interest of the industry, because promoting those interests will help the agent. But even the most well-motivated government agents may experience a form of "epistemic capture," when their backgrounds and experiences lead them to form judgments that are misaligned with the interests of their principals.

The fourth source of misalignment derives from the complex, multi-faceted objectives of the government-agent. For example, before the creation of the CFPB by the Dodd-Frank Act, the Federal Reserve Board (FRB) and the Office of the Comptroller of the Currency (OCC) were responsible for consumer protection (in the consumer finance space). But these same agencies were also responsible for ensuring the safety and soundness of financial institutions. These two objectives sometimes pulled in different directions, leading to insufficient focus on the interests of consumers, thus producing a principalagent relationship that was far from ideal (Bar-Gill \& Warren 2008, 88-90).

By drawing attention to behavioral biases, BPAT suggests some distinctive benefits from delegation, overlooked by standard PAT, but it also shows that delegation entails another and potentially serious cost, one that should play a large role in the emerging field of behavioral public choice. An agent with misaligned interests can take advantage of the imperfectly rational principal. A principal might trust an agent who is not trustworthy. A financial adviser might suggest a package of investments that reflect a conflict of interest (in the form of economic benefits, for the agent, from certain choices) (Council of 
Economic Advisors 2015). Similar concerns about an underappreciated conflict of interest have been raised with respect to mortgage brokers as agents. ${ }^{22}$ In such cases, principals might need some kind of strategy to control the risk that they will be too trusting. ${ }^{23}$

An imperfectly rational principal might also overestimate the informational advantage or expertise of the agent. Agents are not always as competent as they appear to be: The investment adviser might hold mistaken beliefs about the advantages of active management. The mortgage broker might offer false advice about when to refinance a mortgage (Agarwal, Driscoll, \& Laibson 2013). More generally, optimistic bias might lead a principal to discount the risks associated with a delegation of authority. We could imagine an array of heuristics that could lead to undue trust, including the availability heuristic (leading to trust because of recent or salient examples of trustworthiness), the representativeness heuristic (leading to trust because the relevant agent "looks like" a trustworthy type), and the affect heuristic (leading to trust because of an immediate, but unreliable, positive affective reaction).

\section{Competing (or Complementary) Delegations}

The analysis thus far has presented a binary choice between delegation and no delegation. In the next Part we will consider different degrees of delegation, but even then the 
question will be how should decisionmaking powers be allocated between the individualprincipal and the government-agent. This two-party framework is, in some cases, incomplete. The two-party framework assumes that any decision-making power that is not delegated to the government-agent remains with the individual-principal. In particular, no delegation has been taken to mean that the individual makes the decision. In many cases, the individual does exactly that, and no delegation is involved.

Importantly, however, an absence of delegation to a government-agent does not necessarily mean 'no delegation.' Rather, it could entail (implicit) delegation to another agent, usually a market agent. In the consumer protection context, when the regulator has less decisionmaking powers, sellers have more decisionmaking powers. The question then becomes: who is the better agent - the government or the market? (Gillette 2004)

If the government does not regulate a certain market, then sellers-as-agents have more leeway to influence the decisions of consumers-principals. If all consumers are perfectly rational, then we would expect them to delegate to sellers only when such delegation is optimal. If consumers are imperfectly rational, then sellers might obtain excessive decisionmaking powers. They might offer products or services that are harmful to consumers, or steer consumers towards products or services that are less beneficial (to consumers), but more profitable (to sellers). 
Moving from a two-party framework to a three-party framework suggests an additional role for the government: the government-agent can help the individual-principal monitor the seller-agent. It is impossible, in many cases, to strip sellers from all decisionmaking powers. And, in most cases, it would be undesirable to do so. Sellers possess valuable information and can serve as effective agents. Still, sellers' incentives generally are not perfectly aligned with those of consumers. A sophisticated individual-principal would want to monitor the seller-agent - perhaps through disclosure requirements, perhaps through more aggressive requirements of various sorts (Loewenstein, Cain, \& Sah 2011). And government can help. In some cases, two agents are better than one (Varian 1990).

Finally, we note that, even without the introduction of market agents, regulation-asdelegation often involves multiple agents. In the reality of the regulatory state, multiple agencies sometimes have jurisdiction over a single personal decision, which creates both opportunities and challenges. The Environmental Protection Agency and the National Highway Traffic Safety Administration both serve as our agents, influencing features of the vehicles that we purchase; personal decisions are a part of their analysis (Gayer \& Viscusi 2013). The CFPB and the FTC both serve as our agents in the consumer finance space. The Office of Information and Regulatory Affairs, in its role as overseer of (among other things) cost-benefit analysis at other agencies, serves as another agent (Sunstein 2014a). In some personal decisions, Congress and the courts play key roles, and can also be counted as agents of the individual-principal. And in some cases, federal 
agencies share authority with state agencies, further contributing to the multiple-agent problem. ${ }^{24}$

\section{Optimal Delegation}

Delegation is not a binary choice - to delegate or not to delegate. There are different degrees and different forms of delegation. The Regulation-as-Delegation model recharacterizes known regulatory tools as mechanisms for implementing different degrees and forms of delegation. We begin by describing how different regulatory tools implement different degrees of delegation. We then offer guidance on how to choose the optimal degree of delegation.

\section{A. Degrees of Delegation}

It is useful to begin with the two polar options: no delegation and complete delegation. No delegation corresponds to a hands-off, free market approach. ${ }^{25}$ The government does nothing (aside from the imposing the constraints of the common law - an admittedly important aside (Hale 1923)), leaving individuals to make personal decisions on their own. At the other extreme, complete delegation gives all of the decisionmaking power to the government agent, leaving no role for the individual. Mandates and bans are examples of complete delegation. The government decides that late fees in credit cards 
and prepayment penalties in mortgage contracts cannot exceed a specified level. The individual has no say in the matter. She cannot choose a credit card with a higher late fee or a mortgage with a larger prepayment penalty, even if these products are beneficial to her.

Complete delegation can be further divided between rule-based delegation and standardbased delegation. (For related discussion, see Thaler \& Shefrin (1981).) Rule-based full delegation occurs when the government-agent decides to mandate or ban a specific course of action. Standard-based full delegation occurs when the decision is exercised ex post by a judge or an administrative agency following a fact-intensive inquiry (Kaplow 1992).

In between these polar options, there are several types of partial delegation. The most important include (1) information delegation, (2) veto-based delegation, (3) incentive delegation, and (4) commitment delegation. We discuss each of them in turn. ${ }^{26}$

1. Information delegation. Understood as principals, people often want to make the ultimate decision, but they are aware that they lack relevant information. They delegate authority to an agent who will find that information and disclose it to them.

With information delegation, the government agent collects information and discloses it to the individual-principal who then makes a decision. Alternatively, the government 
agent requires a third party, e.g., a seller or service provider, to provide information to the individual-principal. A government-sponsored anti-smoking advertising campaign is an example of the former. (Government-formulated warnings that tobacco companies must place on their cigarette packs also fall under this category.) Regulation requiring credit card issuers to disclose, on the monthly bill, the total interest and fees paid from the beginning of the year is an example of the latter. ${ }^{27}$ There are of course vigorous discussions about the effectiveness of information disclosure, but there is no doubt that it has become a pervasive regulatory tool, and that its popularity stems in part from the fact that it maintains freedom of choice for individual-principals (Ben-Shahar \& Schneider 2014).

Information delegation may seem minimalist, closer to the no delegation end of the spectrum. After all, the agent is just providing information and the principal makes the decision. But any particular disclosure requirement has a degree of selectivity. Government requires automobile manufacturers to disclose information about fuel economy, but not about the vehicle's ability to accelerate or the likelihood that it will require repair. By virtue of their very selectivity, disclosure requirements are not quite minimalist. Therefore, even with information delegation, there is a risk of moral hazard, since the agent usually has (at least some) discretion over what information to collect and how to disclose it (framing).

In a behavioral model, information delegation provides even more power to the agent, 
who can significantly influence the principal's decision through both the substance and framing of the disclosed information. For example, an emphasis on losses, rather than gains, might produce a larger effect on the principal. BPAT draws attention to this point. Individual-principals might not be well-attuned to the importance of framing, and so the power to frame might be abused by the government-agent, certainly if it has its own interests or those of powerful private groups in mind. In addition, individual-principals might underestimate the risks arising when the relevant information is complex and might be treated as mere background noise or when the information influences non-deliberative (System 1) processes (Bar-Gill \& Ferrari 2010; Bubb 2015).

There is also a concern that uninformed, boundedly rational individual-principals might draw false inferences from the disclosed information. Consider the example of genetically modified food products (or GMOs - food products with Genetically Modified Organisms). The best available scientific evidence suggests that GMOs are not harmful to humans and to the environment. Still, state legislatures and government agencies have considered mandates that would require manufacturers of food products to include a GMO disclosure. What would an individual infer from such a disclosure? An informed, rational individual would realize, in light of the evidence, that the disclosure is a product either of interest group pressure or of the government's belief that individuals should be informed even if there is no risk of harm. A less-informed or boundedly rational individual, however, might falsely infer that if the government mandates a GMO disclosure, it must be because GMOs are harmful to heath or to the environment. It is 
certainly plausible that many consumers would, in fact, make that false inference. The concern about false inferences cautions, in some cases, against even the relatively weak information delegation.

2. Veto-based delegation. Under veto-based delegation, the government agent makes a presumptive decision, and the individual-principal can then veto the agent's decision and replace it with a different decision. The informed, expert agent suggests a course of action to the principal, but it is only a suggestion. Veto-based delegation represents default rules as a regulatory technique. Regulatory defaults are common. Examples include retirement savings (Beshears \& Weller 2010), organ donations (in many nations in Europe) (Johnson \& Goldstein 2003), health insurance plans, liability insurance coverage (Johnson, Hershey, Meszaros, \& Kunreuther 1993), and overdraft protection (Willis 2013). Such defaults tend to stick, in part because they contain an implicit recommendation (offered by the principal), in part because of the power of inertia and procrastination (which the principal might be exploiting) (Johsnon \& Goldstein 2013).

The delegation frame offers a new way of thinking about (or even a new justification for) default rules. A principal would wish to delegate to a knowledgeable expert agent the task of investigating possible options and coming up with a recommended course of action. On the other hand, given the potential misalignment of interests between the principal and the agent, the principal would want to reserve the power to reject the agent's recommendation. Default rules thus balance the benefits and costs of delegation, 
and in many cases, the resulting balance is exactly the right one. Of course it is also possible that default rules will lead people to outcomes that they do not like (Rebonato 2011), and also that they will produce opt-outs that are not in people's interests, suggesting that other forms of delegation, including complete delegation via mandates, would be better (Bubb \& Pildes 2014).

Note that our assessment of the degree of delegation implemented through veto-based delegation depends on our model of the principal. In a rational choice framework, vetobased delegation seems closer to the no-delegation end of the spectrum, whereas in a behavioral economics framework, where defaults can be very sticky, veto-based delegation can be much closer to the full delegation end (Rebonato 2011).

3. Incentive delegation. Under incentive delegation, the government agent identifies the optimal course of action and provides the individual-principal with incentives to adopt the identified course of action; the decision remains with the individual-principal. Tax breaks for certain retirement investment vehicles provide an example of carrot-type incentives. A special tax on tobacco products provides an example of stick-type incentives, ${ }^{28}$ as do proposals for some kind of tax on fattening or unhealthy foods (Strnad 2005).

In important respects, incentive delegation is similar to veto-based delegation. In both cases, the government-agent identifies the optimal course of conduct and communicates it 
to the individual-principal. And in both cases the individual-principal retains the power to make the final decision. There are important differences, however. Under veto-based delegation, rejecting the agent's proposal is relatively easy or low-cost, and in the simplest cases, it involves just a "click." (To be sure, opting out of the default can sometimes involve significant transaction costs; and, in a behavioral model, opting out involves additional, psychological costs.) Under incentive delegation, by contrast, deviating from the agent's preferred course of action can entail substantial costs. In this sense, incentive delegation is closer to the full delegation end of the spectrum, at least if the economic incentive is significant.

Another difference between these two forms of delegation has to do with the content of the course of action that the agent recommends. Under veto-based delegation, the agent identifies a specific course of action, e.g., "be an organ donor," "avoid overdraft protection," or "contribute $3 \%$ of your salary to a retirement savings plan." Under incentive delegation, the agent identifies a direction in which a decision should be adjusted, e.g., "save more for retirement" or "smoke less." In this sense, incentive delegation is closer to the no delegation end of the spectrum, as it refrains from identifying a specific course of action (it does not identify a specific level of savings, for example). As the incentive grows in size, of course, the difference between no-delegation and incentive delegation increases.

4. Commitment delegation. A boundedly rational principal who is prone to 
procrastination or might fail to make the optimal decision for other reasons may benefit from commitment mechanisms (Thaler \& Shefrin 1981). The government-principal may effectively provide such mechanisms. We can understand commitment delegation to occur when a principal asks an agent to create some kind of commitment device - as, for example, when a principal makes an arrangement by which a friend, or an institution, imposes penalties or barriers in the event that the principal deviates from a certain course of action (to stop smoking, to lose weight, to save money, to stop gambling) (Ayres 2010). The commitment objective can be achieved by different forms of delegation.

A major example is social security, where the government facilitates a commitment to save for retirement. Other government-regulated retirement vehicles, such as $401(\mathrm{k})$ plans, serve a similar commitment role. Whereas social security illustrates commitment as full delegation, the tax incentives accompanying 401(k) accounts illustrates commitment as incentive delegation. And legislation encouraging employers to switch from opt-in to opt-out retirement plans, illustrates the role of veto-based delegation, working in tandem with incentive delegation, to facilitate commitment (Bubb \& Pildes 2014; Beshears \& Weller 2010). It is plausible to think that commitments might make sense also in other contexts, at least when systematic errors can be shown by uninformed or biased principals (Bhargava, Loewenstein and Sydnor 2015). Of course it is true that commitment delegations, like all other forms, can go wrong for the reasons we have outlined, above all lack of information and misaligned incentives. 


\section{B. The Optimal Degree of Delegation}

In light of this understanding of different regulatory approaches as forms or degrees of delegation, the choice among the different regulatory approaches can be seen as a problem of identifying the optimal degree of delegation. ${ }^{29}$

\section{The Benefits and Costs of Delegation}

We have analyzed the benefits and costs of the delegation decision itself. The same benefits and costs determine the optimal degree of delegation. In many cases, the basic tradeoff is between the relative advantage of the agent as decisionmaker (better information, more expertise, less bias) and the potential misalignment of interests between the principal and the agent. ${ }^{30}$

When the individual-principal has more time, information, and expertise, the benefits from delegation are diminished. The same is true when the individual-principal is more sophisticated and less prone to bias; the debate between those who favor default rules and those who favor education (including financial literacy) and active choosing can be understood in this light. ${ }^{31}$ When principals are sophisticated and unbiased, or can become so (without undue cost), full delegation will rarely be optimal, and active choosing has a great deal of appeal. It is important to add, however, that even sophisticated principals 
may want an agent to collect information for them (information delegation) or to suggest a course of action (veto-based delegation). ${ }^{32}$ For example, the regulation of consumer credit differs from, and entails a greater degree of delegation than, the regulation of corporate credit. ${ }^{33}$ The less sophisticated consumer-principal prefers to delegate more to the government-agent than the more sophisticated corporation-principal.

When the interests of the principal and the agent are further apart, a lower degree of delegation is of course preferable. In such cases, full delegation (mandates and bans) is undesirable, and different forms of partial delegation (veto-based delegation, information delegation, incentive delegation) should be considered. Perhaps even no delegation is best (Glaeser 2006). On the other hand, when the interests of the principal and the agent are more closely aligned, a higher degree of delegation, perhaps even full delegation, become more attractive.

Return, for example, to consumer finance. The optimal degree of delegation depends on the relationship between the interests of the individual-principal and the interests of the government-agent. Before the financial crisis, markets for consumer financial products were regulated mostly by the Federal Reserve Board, the Office of the Comptroller of the Currency and other prudential regulators. These agencies were concerned first and foremost about the safety and soundness of banks. The interests of consumers were but a secondary concern in their regulatory mission. Questions about regulatory capture of some of these agencies suggest an additional wedge between the interests of the 
consumer-principal and those of the government-agent (Bar-Gill \& Warren 2008, 90-91). With such misalignment of interests, the optimal degree of delegation should be quite limited.

The regulatory landscape governing consumer finance has changed significantly after the financial crisis. The Dodd-Frank Act established a new regulator, the Consumer Financial Protection Bureau (CFPB), and structured it in a way that aligns its interests with those of individual consumers. To be sure, any regulator, old or new, poses risks, both because of its potential lack of knowledge and its distinctive incentives. But if it is properly considered a more faithful agent, the CFPB should be granted a higher degree of delegation. Indeed, Congress has granted the CFPB substantial regulatory powers, including the novel power to police "abusive" acts and practices, ${ }^{34}$ apparently in the belief (not unanimously held to be sure) that it will have the proper incentives to protect individual-principals.

\section{Behavioral Factors}

BPAT provides a novel justification for delegation. It also informs the optimal degree of delegation.

Commitment vs. Flexibility. BPAT introduced Commitment Delegation. A principal who is aware of his weakness-of-will would benefit from the availability of commitment 
devices, and would seek out an agent that offers such commitment devices. ${ }^{35}$ For example, such a principal would want his agent to impose large penalties when the principal withdraws funds from his retirement account. In this context, optimal delegation involves a tradeoff between commitment and flexibility. The principal seeks commitment - to facilitate savings and prevent reckless, impulsive withdrawals. But the principal also wants to allow withdrawals for emergency situations and for other well-considered expenses (Koszegi 2014). Another example: An individual-principal who seeks to borrow on favorable terms (specifically, a low interest rate) would like to make a commitment to the lender that he will repay the loan. However, the principal would also like to retain a measure of flexibility and the ability to discharge the loan in bankruptcy if his financial situation becomes dire.

This tradeoff between commitment and flexibility can be implemented through different regulatory tools or different types of delegation. Focusing on complete delegation, the relevant choice is between rule-based and standard-based delegation. The retirement savings example features rule-based delegation: An ex ante mandatory rule specifies a prohibition on early withdrawals and also carves out the exceptions for this prohibition. The magnitude of the penalty for violating the early-withdrawal prohibition reflects the tradeoff between commitment and flexibility. By contrast, the credit-bankruptcy example illustrates the use of standard-based delegation. The individual-principal delegates to a government-agent, the bankruptcy judge, the power to decide whether discharge of the debt is justifiable in the particular circumstances. The stringency of the applied means 
test implements the commitment-flexibility tradeoff.

Prices vs. Sanctions. The choice between incentive delegation and complete delegation depends in part on our assumptions about the knowledge and the rationality of the individual-principal. From a rational choice perspective, complete delegation via bans is conceptually identical to incentive delegation, where the sanction for violating the ban operates as the incentive to follow the government-agent's recommended course of action. ${ }^{36}$ Suppose, for example, that a violator faces a civil penalty of $\$ 100$; that amount operates as an incentive. (To be sure, criminal sanctions can raise distinctive issues.) From a behavioral perspective, however, the two types of delegation operate differently: incentive delegation encourages the principal to make a cost-benefit tradeoff, and a complete delegation does not. A tax on energy-inefficient appliances, designed to encourage energy-efficient choices (and thus to overcome present bias on the part of consumers), allows people to select energy-efficient appliances; a ban on energyinefficient appliances is far more aggressive.

Put differently, with incentive delegation, the individual-principal expressly retains much decision-making power (depending of course on the magnitude of the incentive); this is not the case with complete delegation. (Compare: Cooter 1984; Gneezy \& Rustichini 2000.) Accordingly, when principals are expected to behave rationally, the choice between these two forms of delegation is likely to be less important; a fine is a price. In contrast, the choice between complete delegation and incentive delegation should receive 
careful attention when individuals-principals are imperfectly rational, because a complete delegation will impose far more constraint. Whether this is a virtue or a vice depends on the knowledge and the incentives of both principals and agents. (For relevant discussion, see Conly 2012, 149-52).

Losses vs. Gains. Incentive delegation encompasses both taxes and subsidies. From a rational choice perspective, both forms of regulation influence behavior in a similar way. BPAT, on the other hand, draws a sharp distinction between taxes and subsidies. Research in psychology and behavioral economics has demonstrated the importance of loss aversion and the choice between loss frames and gain frames (Kahneman \& Tversky 1979; Zamir 2014). In short, people dislike losses far more than they like corresponding gains. To the extent that taxes are perceived as losses and subsidies are perceived as gains, loss aversion suggests that taxes will have a stronger behavioral effect (compare: Koszegi 2014). ${ }^{37}$ Incentives that operate through the loss frame thus represent a greater degree of delegation.

Loss aversion also affects the optimal design of veto-based delegation regimes. In particular, when setting the default, the government-agent should consider whether deviation from the default, i.e., exercise of the veto, would be perceived as a loss or a gain. ${ }^{38}$ Deviations from the default are less likely if they are perceived as imposing losses (Sunstein 2013a). For that reason, regulation that operates through the loss frame represents a greater degree of delegation from the individual-principal. 


\section{Hybrid Delegation}

When designing optimal delegation regimes, it is important to recognize that the different regulatory tools are not mutually exclusive. Indeed, optimal delegation can exploit interactions between different regulatory approaches. The result is hybrid delegation.

In particular, disclosure regulation, or information delegation, interacts with other forms of delegation in interesting ways. As a preliminary matter, a central motivation for delegation is the agent's informational advantage. Disclosure can reduce this advantage and with it the need for higher degrees of delegation. Next, consider specific interactions between information delegation and other forms of delegation. For example, information delegation interacts with veto-based delegation: the disclosure empowers the principal to exercise her veto power in an informed way. ${ }^{39}$ In the context of health insurance, the principal might want to be informed, to be able to rely on a default rule, and to be able to opt out of that rule if she decides that opting-out is in her interest. A similar interaction can occur between information delegation and incentive delegation.

The retirement savings problem illustrates several forms of hybrid delegation. Social security as a mandatory rule represents full delegation regarding a base amount of savings. Beyond this base amount, the tax code, through 401(k) accounts, represents incentive delegation. In addition, the law encourages employers automatically to enroll 
their employees in their retirement savings plans, subject to opt-out, representing vetobased delegation. Finally, mandatory disclosures, or information delegation, facilitate the operation of both the incentive and veto-based delegations. In many contexts, information delegation and veto-based delegation provide an especially attractive combination.

\section{REVERSE DELEGATION}

We have thus far described the individual as principal and the government as agent. We now introduce an opposite paradigm - reverse delegation, where the government is the principal and the individuals are the agents. If the issue involves personal decisions, namely decisions that mainly affect a single individual, it is natural to think about the individual as a principal who may choose to delegate all or part of her decisionmaking powers to a government agent. Reverse delegation captures a different set of problems public good problems. Here the government-principal, as representative of the People, sets a public objective - a clean, sustainable environment, financial stability, higher educational attainment - and enlists individuals-agents to help attain this objective. ${ }^{40}$

We do not mean, of course, to suggest that government is always public-spirited, or that it invariably has public objectives in mind. Recall our emphasis on the imperfect motivations of public officials and the importance of behavioral public choice. Our only 
claim is that insofar as those officials are seeking to address public good problems, reverse delegation will play an important role.

\section{A. Conceptualizing Reverse Delegation}

Reverse delegation re-characterizes the different regulatory approaches. The extreme approach of no delegation is represented by a centralized, command-and-control economy. A free market economy lies at the other, full delegation side of the spectrum. ${ }^{41}$ In terms of regulatory tools, bans and mandates represent no delegation (from the government as principal), whereas no regulation represents complete delegation (to individuals as agents). Disclosure mandates, default rules, taxes and subsidies remain intermediate forms of (reverse) delegation.

As in the personal decisions space, the optimal degree of delegation depends on the relative competencies of the principal and the agent. When government has the relevant information and expertise, along with the proper incentives, it should retain more control and delegate less. And when information is decentralized, including information about the preferences of the different individuals-agents and the constraints that they face, more delegation is warranted.

But information and competence are not the only considerations. The government- 
principal should not fully delegate public good decision even to perfectly informed, perfectly rational individuals, to the extent that these individuals might ignore the external effects of their decisions. ${ }^{42}$ Consider the externality problem -- specifically, the concern that individual-agents will ignore external effects that greatly matter to the government-principal. The externality problem is similar to the misalignment-of-interests problem that we emphasized when discussing (direct) delegation of personal decisions. As misalignment of interests justified less (direct) delegation, the externality problem in the public good context places a thumb on the scale, sometimes a heavy thumb, pushing towards less (reverse) delegation.

Finally, ideology and politics impose bounds on optimal delegation. Liberal democracies require substantial delegation, whereas authoritarian regimes might not tolerate more than a modicum of delegation. Even in the context of public good problems, there are strong reasons to follow the path of liberal democracies, as we shall now see. ${ }^{43}$

\section{B. Illustrating Reverse Delegation}

To assess the usefulness of the reverse delegation frame for the regulation of public goods, consider the following examples:

Environmental protection. The government wants to reduce pollution and minimize the 
adverse effects of climate change. There are many steps that the government-principal can take on its own. It can decide to purchase electricity only from "green" power plants. It can replace its vehicle fleet with hybrid cars (or others that have good fuel economy). The impact of such steps depends on the relative size of the government sector. In any event, to achieve its environmental protection objective, the government-principal would also like to influence the behavior and decisions of private parties - of individuals-agents. Such influence can take many forms. It can be heavy-handed, leaving no discretion for the individual - the no delegation option. For example, the government can ban the discharge of certain pollutants.

But the government-principal can also influence individual decisions using intermediate levels of delegation. Incentive delegation, specifically tax breaks, can be used to encourage the purchase of fuel-efficient vehicles (Bubb \& Pildes 2014). Disclosure delegation can be used to reduce energy consumption. For example, the government may require prominent disclosure of a vehicle's mpg rating, or may take steps to ensure that consumers learn about the environmental consequences of fuel-inefficient vehicles (id.). Or invoking behavioral insights, the government can require utility companies to disclose, on the monthly bill, how an individual's electricity consumption compares to that of her neighbors (Allcott 2011). And default rules might be used to favor environmentally preferred technologies, subject to opt-out (Sunstein \& Reisch 2014; Pichert \& Katsikopoulos 2008). 
Here as elsewhere, the optimal degree of delegation depends on questions of information and competence. If the government-principal concluded, with justified confidence, that the harm from releasing a certain pollutant into the atmosphere outweighs the benefits of the activity that generated this pollutant, then no delegation is necessary and a simple ban is justified. In other cases, the cost-benefit tradeoff is less obvious. More importantly, the tradeoff may well depend on information that the individual-agent has and that the government-principal does not. The decision whether to buy a hybrid car depends on the individual's driving patterns. Decisions affecting the amount of electricity consumed depend on household-specific information - tolerance for certain levels of heat and cold, the number and ages of the children, the insulation of the house, and so forth. The government-principal lacks the information needed to make the decision, and it would be inefficient for the government-principal to acquire the necessary information. Some kind of delegation is the optimal solution, perhaps in the form of incentives or default rules rather than mandates or bans.

Healthcare. The government wants to reduce healthcare costs, and thus the budget deficit. One way to accomplish this is by inducing individuals-agents to make healthier food choices, ${ }^{44}$ to stop smoking, and to make better healthcare and prescription drug choices. Note that by hypothesis, the objective is to reduce the toll on the federal budget, not to improve the health of individual citizens. The latter would be a personal decision, analyzed through the direct delegation frame, rather than the reverse delegation frame. But, of course, the two policy objectives are closely related. Healthier individuals means 
lower healthcare costs.

Government spending on healthcare depends critically on a great multitude of individual lifestyle decisions and healthcare choices. For many of these decisions, there is no single correct choice. A great deal depends on varying values and tastes. What to eat, how much to exercise, which healthcare plan to choose - they all depend on the individual-agent's preferences and circumstances. Consistent with Mill's central plea, the necessary information is located with the individual-agent. And, therefore, delegation is optimal. In some cases, where the government-principal has more information, it will choose a lesser degree of delegation. For example, the government can impose certain minimum requirements on health insurance plans. In other cases, a higher degree of delegation would be optimal. Perhaps most common in this space is information delegation - from nutrition labels to warnings on cigarette packages (Loewenstein, Sunstein, \& Golman 2014).

Importantly, BPAT tells us that, even within the information delegation category, some disclosure techniques entail more delegation than others. Some disclosures are purely informative, assisting the individual-agent in making the optimal, deliberative choice. Other disclosures, such as graphic anti-smoking advertisements, are designed to trigger an emotional response, and provide a stronger nudge in a specific direction (Jolls 2013; Bubb 2015). The latter approach should be taken by a government-principal that is better informed and has less confidence in the decisionmaking abilities of its individuals-agents. 
Saving. The government wants to increase saving, because of the macroeconomic benefits and to reduce the cost of welfare programs. One way to accomplish this is by inducing individuals-agents to save more for retirement (Benartzi \& Thaler 2013). As with health, saving is also a personal decision - to be analyzed using the direct delegation frame. But focusing on the aforementioned externalities, saving can also be studied using a reverse delegation frame. Optimal saving decisions depend on individual preferences and circumstances, as well as on the broader macroeconomic effects. From a rationalchoice, PAT perspective the importance of the individual-level factors suggests more delegation to the individuals-agents. BPAT, while recognizing the informational advantage of the individuals-agents, raises concerns about the ability of these agents to make optimal decisions, suggesting less delegation. It follows that some intermediate level of delegation, or hybrid delegation, may be optimal. (See Sec. II.B.3 above; Benartzi \& Thaler 2013.)

Homeownership. The government wants to increase homeownership, because of the positive externalities that (on one view) it is likely to create (DiPasquale \& Glaeser 1999). But it also wants to avoid resort to risky mortgage financing, because of systemic risk. Given the substantial externalities and macroeconomic implications, the government-principal would want to retain much decisionmaking authority. Specifically, the government-agent would ban or severely restrict the use of what it considers to be risky mortgage products. Alternatively, it might impose limits on the securitization of 
mortgage debt.

Note that the government-principal's reluctance to delegate is based in large part on concerns about the individuals-agents' decisionmaking abilities. Imperfectly rational homeowners might fail to appreciate the risks associated with these risky mortgage products. Optimistic or improperly incentivized bankers might make risky securitization decisions (Bar-Gill 2012, Ch. 3; Bubb \& Krishnamurthy 2015).

But, again, homeownership is a very personal decision, based on a host of factors that the individual-agent knows and that the government-principal does not. Mortgage financing decisions can similarly depend on individual preferences and circumstances. It follows that the government-principal would often choose more delegation. Regulation-asdelegation has taken several forms here, primarily incentive delegation, through tax credits for mortgage interest, and information delegation, through public provision of information and through various disclosure mandates imposed on lenders. Veto-based delegation can also be attractive. ${ }^{45}$

A multi-agent approach is also being implemented in the area of mortgage financing. Recognizing the importance of individual-level information, but not trusting the individuals-agents fully to understand the implications of this information, the government-principal is enlisting market-agents to review the individual-level information. The ability-to-repay rules under Dodd-Frank can be understood within this 
multi-agent framework (Dodd-Frank $\S \S 1411,1412,1414$ ).

\section{CONCLUSION}

Our central claim here has been that especially with the help of a behavioral lens, PAT casts fresh light on some persistent problems in the theory and practice of regulation. In the domain of personal decisions, forms of apparent paternalism are not rare, even if they are usually defended and explained in nonpaternalistic terms. Those forms of apparent paternalism might be more readily justified if we see regulation not as an imposition, but as reflecting an implicit delegation. Even if they emerge as unjustifiable, as they sometimes will, the delegation metaphor helps to explain exactly why.

We have seen that under plausible assumptions, sensible principals would delegate authority to public officials, in recognition of limitations in information and time, and of their own behavioral biases. Importantly, the nature of the delegation will differ with context. In some cases, the principal would seek the agent's help, but only in obtaining information. In other cases, the principal would favor incentives or some kind of presumption, which the principal could override if the circumstances warranted. In extreme cases, a rational principal would favor a mandate or a ban. We have attempted to specify the conditions under which one or another approach makes best sense. By pointing to the risks of excessive and insufficient delegation, BPAT enriches the standard 
analysis.

We have emphasized that the delegations here are hypothetical rather than actual (but see Sunstein 2015a, Bar-Gill and Sunstein 2015), and to that extent, BPAT cannot entirely resolve debates about the appropriate role of governments in such domains as food safety, retirement planning, energy efficiency, occupational safety and health. But by establishing that rational principals would favor the use of agents, we have argued that ultimate conclusions depend not on anything abstract or ineffable, but largely on the costs of decisions and the costs of errors.

Shifting from personal decisions to public goods problems, we have shown that, here too, BPAT sheds new light on the theory and practice of regulation. Now it is the government as principal that decides on the optimal degree of delegation to the individuals-agents, and a regulatory technique that entailed minimal delegation in the personal decisions context implies maximal (reverse) delegation. The important point is that a similar framework - balancing decision costs and error costs - applies. In our view, an understanding of that framework helps to illuminate a wide range of domains in which government is effectively delegating authority to individuals to solve public goods problems, and in which it is required to select appropriate tools. 


\section{List of References}

Ackerman, Bruce. 1993. We the People Vol. 1: Foundations. Cambridge, MA: Belknap Press.

Agarwal, Sumit, John C. Driscoll, \& David I. Laibson. 2013. Optimal Mortgage Refinancing: A Closed-Form Solution. 45 J. Money, Credit \& Banking 591-622.

Aghion, Philippe, \& Jean Tirole. 1997. Real and Formal Authority in Organization. 105 J. Pol.Econ. 1-29.

Allcott, Hunt. 2011. Social Norms and Energy Conservation. 95 J. Pub. Econ. 10821095.

Arlen, Jennifer, Matthew Spitzer, \& Eric Talley. 2002. Endowment Effects within Corporate Agency Relationships. 31 J. Legal Stud. 1-37.

Arlen, Jennifer, \& Stephan W. Tontrup. 2015. Does the Endowment Effect Justify Legal Intervention? The Debiasing Effect of Legal Institutions. 44 J. Legal Stud. 143182.

Arrow, Kenneth. 1964. Research in Management Controls: A Critical Synthesis. In C. P. Bonini, R. K. Jaedicke, \& H. M. Wagner eds., Management Controls: New Directions in Basic Research 317-327. New York: McGraw-Hill.

Ayres, Ian. 1998. Default Rules for Incomplete Contracts. In Peter Newman ed., 1 The New Palgrave Dictionary for Economics and the Law 585-586. New York: Stockton Press.

Ayres, Ian, \& Robert Gertner. 1989. Filling Gaps in Incomplete Contracts: An Economic Theory of Default Rules. 99 Yale L.J. 87-130. 
Ayres, Ian. 2010. Carrots and Sticks: Unlock the Power of Incentives to Get Things Done. New York City: Bantam.

Bamberger, Kenneth A. 2006. Regulation as Delegation: Private Firms, Decisionmaking, and Accountability in the Administrative State. 56 Duke L.J. 377-468.

Bar-Gill, Oren. 2012. Seduction by Contract: Law, Economics, and Psychology in Consumer Markets. Oxford: Oxford University Press.

Bar-Gill, Oren, Michal Barzuza, \& Lucian A. Bebchuk. 2006. The Market for Corporate Law. 162 J. Institutional \& Theoretical Econ. 134-172.

Bar-Gill, Oren, \& Franco Ferrari. 2010. Informing Consumers about Themselves. 3 Erasmus L. Rev. 93-119.

Bar-Gill, Oren, \& Cass R. Sunstein. 2015. Regulation As Delegation: Survey Evidence. Unpublished Manuscript.

Bar-Gill, Oren, \& Elizabeth Warren. 2008. Making Credit Safer. 157 U. Pa. L. Rev. 1101.

Barr, Michael S., Sendhil Mullainathan, \& Eldar Shafir. 2009. The Case for Behaviorally Informed Regulation. In D. Moss \& J. Cisternino, eds., New Perspectives on Regulation 25-61.

Barr, Michael S., Sendhil Mullainathan, \& Eldar Shafir. 2008. Behaviorally Informed Financial Services Regulation. New America Foundation.

Bebchuk, Lucian A., \& Steven Shavell. 1991. Information and the Scope of Liability for Breach of Contract: The Rule of Hadley v. Baxendale. 7 J.L. Econ \& Org. 284312. 
Bebchuck, Lucian A. 1992. Federalism and the Corporation: The Desirable Limits on State Competition in Corporate Law. 105 Harv. L. Rev. 1443-1510.

Benartzi, Shlomo, \& Richard H. Thaler. 2013. Behavioral Economics and the Retirement Savings Crisis. 339 Science 1152-1153.

Ben-Shahar, Omri, \& Carl E. Schneider. 2014. More Than You Wanted to Know: The Failure of Mandated Disclosure. Princeton: Princeton University Press.

Beshears, John, \& Brian Weller. 2010. Public Policy and Saving for Retirement: The “Autosave” Features of the Pension Protection Act of 2006. In John Siegfried ed., Better Living Through Economics 274-290.

Bhargava, Saurabh, George Loewenstein, \& Justin Sydnor. 2015. Do Individuals Make Sensible Health Insurance Decisions? Evidence from a Menu with Dominated Options. Working Paper. Available at: www.nber.org/papers/w21160.

Bhargava, Saurabh, \& George Loewenstein. 2015. Behavioral Economics and Public Policy 102: Beyond Nudging. 105 American Economic Review 396-401.

Bubb, Ryan, \& Patrick L. Warren. 2014. Optimal Agency Bias and Regulatory Review. 43 J. Legal Stud. 95-135.

Bubb, Ryan, \& Richard Pildes 2014. How Behavioral Economics Trims Its Sails and Why. 127 Harv. L. Rev. 1593-1678.

Bubb, Ryan. 2015. TMI? Why the Optimal Architecture of Disclosure Remains TBD. 113 Mich.L.Rev. 1021-1042. 
Bubb, Ryan, \& Prasad Kirshnamurthy. 2015. Regulating Against Bubbles: How Mortgage Regulation Can Keep Main Street and Wall Street Safe-From Themselves. 163 U. Pa. L. Rev. Forthcoming.

Bubb, Ryan, \& Patrick L. Warren. A Behavioral Contract Theory Model of Retirement Savings. Working Paper.

Canetti, Laura, Eytan Bachar, \& Elliot M. Berry. 2002. Food and Emotion. 60 Behav. Processes 157-164.

Chetty, Raj. 2015. Behavioral Economics and Public Policy: A Pragmatic Perspective. 105 American Economic Review 1-33.

Cook, Brian J., \& B. Dan Wood. 1989. Principal-Agent Models of Political Control of Bureaucracy. 83 Am. Pol. Sci. Rev. 965-978.

Cooter, Robert. 1984. Prices and Sanctions. 84 Colum. L. Rev. 1523-1560.

Conly, Sarah. 2012. Against Autonomy. 2-12. Cambridge: Cambridge University Press. Council of Economic Advisers. 2015. The Effects of Conflicted Investment Advice on Retirement Savings. Available at: http://www.whitehouse.gov/sites/default/files/docs/cea_coi_report_final.pdf

Danz, David, Dorothea Kübler, Lydia Mechtenberg, \& Julia Schmid. 2015. On the Failure of Hindsight-Biased Principals to Delegate Optimally. Forthcoming in Management Science.

DellaVigna, Stefano, \& Ulrike Malmendier. 2006. Paying Not to Go to the Gym. 96 Am. Econ. Rev. 694-719. 
DiPasquale, Denise, \& Edward Glaeser. 1999. Incentives and Social Capital: Are Homeowners Better Citizens? 45 J. Urban Econ. 354-384.

Easterbrook, Frank H. \& Daniel R. Fischel. 1989. The Corporate Contract. 89 Colum. L. Rev. 1416-1448.

Ellickson, Robert. 1994. Order Without Law. Cambridge, MA: Harvard University Press

Fama, Eugene. 1980. Agency Problems and the Theory of the Firm. 88 J. Pol. Econ. 288307.

Fehr, Ernst, Holger Herz, \& Tom Wilkening. 2013. The Lure of Authority: Motivation and Incentive Effects of Power. 103 Am. Econ. Rev. 1325-1359.

Freeman, Jody, \& Jim Rossi. 2012. Agency Coordination in Share Regulatory Space. 125 Harv. L. Rev. 1131-2201.

Fried, Barbara. 2002. The Progressive Assault on Laissez-Faire. Cambridge, MA: Harvard University Press.

Gayer, Ted, \& W. Kip Viscusi. 2013. Overriding Consumer Preferences with Energy Regulations. 43 Journal of Regulatory Economics 248-264.

Gayer, Ted, \& W. Kip Viscusi. 2015. Behavioral Public Choice: The Behavioral Paradox of Public Policy. Working Paper.

Gersen, Jacob E. 2010. Designing Agencies. In Daniel A. Farber and Anne Joseph O'Connell eds., Research Handbook on Public Choice and Public Law.

Gneezy, Uri, \& Aldo Rustichini. 2000. A Fine is a Price. 29 J. Legal Stud. 1-17.

Glaeser, Edward L. 2006. Paternalism and Psychology. 73 U. Chi. L. Rev. 133-156.

Gigerenzer, Gerd. 2014. Risk Savvy: How to Make Good Decisions. London: Penguin. 
Gigerenzer, Gerd. 2015a. On the Supposed Evidence for Libertarian Paternalism. Review of Psychology and Philosophy 1-23.

Gigerenzer, Gerd. 2015b. Simply Rational: Decision Making in the Real World. Oxford: Oxford University Press.

Gillette, Clayton P. 2004. Rolling Contracts as an Agency Problem. 2004 Wis. L. Rev. $679-722$.

Gomez-Mejia, Luis R., \& Robert M. Wiseman. 1998. A Behavioral Agency Model of Managerial Risk Taking. 23 Academy of Management Review 133-153.

Grüne-Yanoff, Till, and Ralph Hertwig. 2015. Nudge Versus Boost: How Coherent are Policy and Theory? Minds and Machines 1-35.

Hale, Robert L. 1923. Coercion and Distribution in a Supposedly Non-coercive State. 38 Political Science Quarterly 470-494

Hayek, F. A. 2014. The Market and Other Orders. Chicago: Chicago University Press. Hermalin, Benjamin E. 1993. Managerial Preferences Concerning Risky Projects. 9 J.L. Econ.\& Org. 127-135.

Holmstrom, Bengt, \& Paul Milgrom. 1991. Multitask Principal-Agent Analysis: Incentive Contracts, Asset Ownership and Job Design. 7 J.L. Econ . \& Org. 24-52.

Johnson, Eric J., John Hershey, Jacqueline Meszaros, \& Howard Kunreuther. 1993. Framing, Probability Distortions, and Insurance Decisions. 7 J. Risk \& Uncertainty 33-51.

Johnson, Eric J., \& Daniel G. Goldstein. 2003. Do Defaults Save Lives? 302 Science 1338-1339. 
Johnson, Eric K., \& Daniel G. Goldstein. 2013. Decisions by Default. In Eldar Shafir ed., Behavioral Foundations of Policy 417-427.

Jolls, Christine. 2013. Product Warnings, Debiasing, and Free Speech: The Case of Tobacco Regulation. 169 J. Institutional \& Theoretical Econ. 53-78.

Kahneman, Daniel, \& Amos Tversky. 1979. Prospect Theory: An Analysis of Decision Under Risk. 47 Econometrica 263-291.

Kaplow, Louis. 1992. Rules Versus Standards: An Economic Analysis. 42 Duke Law Journal 557-692.

Koszegi, Botond. 2014. Behavioral Contract Theory. 52 J. Econ. Literature 1075-1118.

Laffont, Jean-Jacques, \& David Martimort. 2002. The Theory of Incentives: The Principal-Agent Model. Princeton: Princeton University Press.

Laibson, David. 2015. Why Don't Present-Bias Agents Make Commitments. 105 Am. Econ. Rev. 267-72.

Lewis, Michael. 2012. Obama’s Way. Vanity Fair.

Leymore, Saul. 2014a. From Helmets to Savings and Inheritance Taxes: Regulatory Intensity, Information Revelation, and Internalities. 81 University of Chicago Law Review 229-249.

Leymore, Saul. 2014b. Internality Regulation Through Public Choice. 15 Theoretical Inquiries in Law 447-470.

Loewenstein, George, Daylian M. Cain, and Sunita Sah. 2011. The Limits of Transparency: Pitfalls and Potential of Disclosing Conflicts of Interest. $101 \mathrm{Am}$. Econ. Rev. $423-428$ 
Loewenstein, George, Cass R. Sunstein, \& Russell Golman. 2014. Disclosure:

Psychology Changes Everything. 6 Annual Rev. Econ 391-419.

Mill, John Stuart. 1869. On Liberty. London: Longman, Roberts, \& Green Co.

Mullainathan, Senhil, \& Eldar Shafir. 2013. Scarcity: Why Having Too Little Means So Much. New York: Times Books.

Mylovanov, Tymofiy. 2008. Veto-Based Delegation. 138 J. Econ. Theory 297-307.

Ostrom, Elinor. 1990. Governing the Commons. Cambridge: Cambridge University Press.

Pepper, Alexander. 2015. Behavioral Agency Theory: New Foundations for Theorizing About Executive Compensation. 41 Journal of Management 1045-1068.

Pichert, Daniel, \& Kostantinos V. Katsikopoulos. 2008. Green Defaults: Information Presentation and Pro-Environmental Behavior. 28 J. Env. Psych. 63-73.

Porat, Ariel, \& Lior J. Strahilevitz. 2014. Personalizing Default Rules and Disclosure with Big Data. 112 Mich. L. Rev. 1417-1519.

Pronin, Emily. 2002. The Bias Blind Spot: Perceptions of Bias in Self Versus Others. 28 Pers. Soc. Psychol. Bull. 369-381.

Rawls, John. 1971. A Theory of Justice. Cambridge: Harvard University Press.

Rebonato, Riccardo. 2012. Taking Liberties: A Critical Examination of Libertarian Paternalism. London: Palgrave Macmillan.

Schnellenbach, Jan, \& Christian Schubert. 2015. Behavioral Public Choice: A Survey. European Journal of Political Economy, Forthcoming.

Shah, Anuj K., Eldar Shafir, and Sendhil Mullainathan. 2015. Scarcity Frames Value. 26 Psychological Science 402-412. 
Sharot, Tali. 2011. The Optimism Bias: A Tour of the Irrationally Positive Brain.

London: Vintage.

Strnad, Jeff. 2005. Conceptualizing the "Fat Tax": The Role of Food Taxes in Developed Economies. 78 Southern California Law Review 1221-1326.

Sunstein, Cass R. 2013a. Deciding by Default. 162 U. Pa. L. Rev. 1-57.

Sunstein, Cass R. 2013b. The Storrs Lectures: Behavioral Economics and Paternalism. 122 Yale L.J. 1826-1899.

Sunstein, Cass R. 2014a. Valuing Life. Chicago: University of Chicago Press.

Sunstein, Cass R. 2014b. Choosing Not to Choose. 64 Duke L.J. 1-52.

Sunstein, Cass R., \& Lucia Reisch. 2014. Automatically Green. 38 Harv. Env. L. Rev. $127-158$.

Sunstein, Cass R. 2015a. Do People Like Nudges? Unpublished manuscript, available at http://papers.ssrn.com/sol3/papers.cfm?abstract_id=2604084.

Sunstein, Cass R. 2015b. Which Nudges Do People Dislike? A Nationally Representative Survey. Unpublished Manuscript.

Thaler, Richard H., et al. 2013. Choice Architecture. In Eldar Shafir ed., The Behavioral Foundations of Public Policy.

Thaler, Richard H., \& H.M. Shefrin. 1981. An Economic Theory of Self-Control. 89 J. Polit. Econ. 392-406.

Ulmann-Margalit, Edna. 1976. The Emergence of Norms. Oxford: Oxford University Press. 
Varian, Hal R. 1990. Monitoring Agents with Other Agents. 146 J. Institutional and Theoretical Econ. 153-174.

Vermeule, Adrian. 2015. The Administrative State: Law, Democracy, and Knowledge. In Mark Tushnet et al eds., Oxford Handbook of the United States Constitution.

Waldfogel, Joel. 2009. Scroogenomics: Why You Shouldn't Buy Presents for the Holidays. Princeton: Princeton University Press.

Wansink, Brian. 2014. Slim by Design. New York: William Morrow.

Warren, Patrick L., \& Daniel H. Wood. 2015. The Political Economy of Regulation in Markets with Naïve Consumers. 12 J. Eur.Econ. Ass'n 1617-1642.

Weyand, Jerry. 1996. Micromanagement: Outmoded or Alive and Well? 85 Mgmt. Rev. 62.

Willis, Lauren E. 2011. The Financial Education Fallacy. 101 Am. Econ. Rev. 429-434.

Willis, Lauren E. 2013. When Nudges Fail: Slippery Defaults. 80 U. Chi. L. Rev. 11151229.

Yellen, Janet L. 1984. Efficiency Wage Models of Unemployment. 74 Am. Econ. Rev. 200-205.

Zamir, Eyal. 2014. Law, Psychology, \& Mortality: The Role of Loss Aversion. Oxford: Oxford University Press.

Zywicki, Todd J. 2012. The Economics and Regulation of Bank Overdraft Protection. 69 Wash. \& Lee L. Rev. 1141-1200. 
* Professor of Law and Economics, Harvard Law School.

** Robert Walmsley University Professor, Harvard Law School. We are grateful to Meirav Furth and Lisa Marrone for excellent research assistance. For helpful comments and discussions, we thank John Beshears, Ryan Bubb, Jacob Gersen, David Laibson, Oliver Hart, Daryl Levinson, and Matthew Stephenson. We are especially grateful to the editors of the JLA and to the referee for their comments and suggestions.

${ }^{1}$ For a critical review, see Vermeule 2015. PAT has also been used in political science to characterize and analyze relationships between different government actors, e.g., President and administrative agencies or Congress and administrative agencies (See: Cook \& Wood 1989; Gersen 2010).

${ }^{2}$ Saul Levmore's work $(2014 \mathrm{a} ; 2014 \mathrm{~b})$ on regulation responding to internalities overlaps with our "personal decisions." Like us, Levmore writes of individuals soliciting the help of government in dealing with their internalities problems.

${ }^{3}$ At the same time, the issue of third-party effects has to be investigated, rather than asserted, when people run risks. For example, premature mortality might reduce, rather than increase, costs for the welfare system, taken as a whole.

${ }^{4}$ A behavioral lens has been added to PAT in other contexts (See: Gomez-Mejia \& Wiseman 1998; Pepper 2015; See also: Leymour 2014a; 2014b).

${ }^{5}$ Relevant discussion can be found in Thaler \& Shefrin (1981). Influenced by principal-agent models, Thaler and Shefrin explore the possibility of dual-self models in which the Planner, acting as a kind of principal, constrains the Doer. One of the relevant strategies involves the issuance of binding rules. With modest adjustments, the same approach can be used in cases in which regulation operates as a delegation. 
${ }^{6}$ For complementary discussion, which could be adapted to incorporate BPAT, see Chetty (2015) in particular at 25: "Further work is needed to determine whether and how subjective well-being metrics can be used to reliably measure experienced utility, but they appear to offer at least some qualitative information on ex post preferences than can help mitigate concerns about paternalism in behavioral welfare economics."

${ }^{7} \mathrm{We}$ emphasize, however, that citizens generally might self-consciously delegate certain decisions to public officials, and very much for the reasons we discuss. See Conly (2012) for detailed discussion.

${ }^{8}$ Or maybe even metaphorical delegation, namely, delegation under PAT as a metaphoric lens for evaluating and designing optimal regulation (Compare: Vermeule 2015).

${ }^{9}$ In a private, market setting delegation would entail a cost - the agent's fee. Some individuals would be able to afford this fee, while others would not. Delegation to a government agent, even if this agent is not as good as the private agent, can serve distributional or equality goals. Note that the existence of a government agent does not preclude individuals from employing a second, private agent, as long as the law does not mandate full delegation (see below).

${ }^{10}$ For an emphasis on this point in the context of savings behavior, and an argument in favor of considering mandates, see Bubb \& Pildes (2014).

${ }^{11}$ There is a close connection between the idea of hypothetical consent and social contract theory - in fact, the two may be identical. For the most influential modern version of social contract theory, see Rawls (1971). Note as well that while we are focusing on hypothetical consent, we believe that actual consent might also be found for many delegations, at least from majorities; further research would be most valuable on that question. For preliminary evidence, see Sunstein (2015a), Bar-Gill and Sunstein (2015).

${ }^{12}$ For relevant discussion, emphasizing the constraints of time scarcity and its effects on "bandwidth," see Mullainathan \& Shafir (2012).

${ }^{13}$ The point is emphasized in Conly (2012) as a justification for mandates and bans.

${ }^{14}$ The standard motivations for delegation were succinctly summarized by Laffont and Martimort (2002, 28): "Delegation can be motivated either by the possibility of benefitting from some increasing returns 
associated with the division of tasks, which is at the root of economic progress, or by the principal's lack of time or lack of any ability to perform the task himself, or by any other form of the principal's bounded rationality when facing complex problems."

${ }^{15}$ For powerful evidence of heuristic-driven errors in the context of health insurance decisions, along with a plea for what we would consider a delegation, see Bhargava, Loewenstein, \& Sydnor (2015). A general argument to this effect can be found in Bhargava \& Loewenstein (2015).

${ }^{16}$ For an extended but partial counterargument, see Gigerenzer (2015b) (arguing that in many domains, even apparently complex ones, it is both best and possible to equip people to make their own choices).

${ }^{17}$ For a discussion of the sophisticated v. naïve distinction, see Laibson $(2015,5)$; DellaVigna \& Malmendier $(2006,714)$. For instance, a less sophisticated agent, suffering from hindsight bias, might choose an inefficiently low level of delegation, after receiving information about an agent's prior mistake (Danz, Kübler, Mechtenberg, \& Schmid 2015).

${ }^{18}$ In their exposition to PAT, or incentive theory, Laffont \& Martimort $(2002,2)$, write: "Conflicting objectives and decentralized information are thus the two basic ingredients of incentive theory."

${ }^{19}$ Moral hazard or hidden action is one of the main problems studied in PAT. The other main problems are "adverse selection" or hidden knowledge (the agent has some private knowledge about his cost or valuation) and nonverifiability (when the principal and the agent share the same information, but no third party (specifically, a court) can observe this information (See: Laffont \& Martimort 2002).

${ }^{20} \mathrm{We}$ bracket the complexities with seeing paternalism as a misalignment of interests. On those complexities, see Conly (2012), distinguishing between ends paternalism and means paternalism; Sunstein (2013b) (same). Obviously the problem of misalignment is reduced when government is genuinely respecting people's ends and merely nudging them toward preferable means for achieving those ends.

${ }^{21}$ This problem is mitigated by big data, which provides the agent with individualized information (Sunstein 2014b, 11; Porat \& Strahilevitz 2014, 1421).

${ }^{22}$ Such concerns were recently addressed by the FRB in a rule banning yield-spread premiums. 12 CFR Part 226 (Federal Register/Vol. 75, No. 185/Friday, September 24, 2010). 
${ }^{23}$ See the proposed regulation from the Department of Labor on the definition of "fiduciary." 29 CFR Parts 2509 and 2510 (Federal Register/Vol. 80, No. 75, April 20, 2015).

${ }^{24}$ The question of fuel economy is an example (See: Rossi \& Freeman 2012).

${ }^{25}$ We bracket some empirical and conceptual problems with this idea. Some form of choice architecture is inevitable, and it will affect what people choose. See Thaler et al. (2013).

${ }^{26}$ Our framework encompasses traditional regulatory approaches, like mandates, bans, taxes and subsidies, as well as regulatory approaches associated with behaviorally-informed policymaking, like default rule design and forced choice. (Disclosure mandates are part of both the traditional and the behavioral approaches.) (Compare: Bubb \& Pildes 2014)

27 See Center for Disease Control and Prevention, Campaign Overview (http://www.cdc.gov/tobacco/campaign/tips/about/campaign-overview.html) (government anti-smoking campaign); Jolls (2013) (warnings on cigarette packs); Bar-Gill (2012, Ch. 2) (credit card disclosures).

${ }^{28}$ In some sense, incentive delegation is the basic form of delegation in the economic PAT literature, which studies how optimally designed incentive schemes mitigate the principal-agent problem (See: Laffont \& Martimort 2002).

${ }^{29}$ This analysis can guide a legislature that decided to "assign" a certain issue to a regulatory agency and must now decide what powers, i.e., regulatory tools to give the agency. It can also provide guidance to an agency that needs to choose among the different regulatory tools at its disposal.

${ }^{30}$ In some cases, there won't even be an advantage to trade-off against the potential misalignment of interests, e.g., when, for good Millian reasons, the agent lacks information that the principal has.

${ }^{31}$ See, e.g., Gigerenzer (2014) (generally arguing for education); Willis, (2011) (arguing that financial education does not work and that default rules would be better). See generally Grüne-Yanoff \& Hertwig (2015).

${ }^{32}$ Not surprisingly, veto-based delegation has been shown to be superior to full delegation, when the individual-principal is expected to make better decisions after rejecting the government-agent's suggestion (when the suggestion is rejected) (See Mylovanov 2008). 
${ }^{33}$ The new Consumer Financial Protection Bureau was endowed with substantial powers to regulate the consumer credit market. See www.consumerfinance.gov. There is no comparable regulator, or comparable regulatory powers, for corporate credit.

${ }^{34}$ The ability to "design" an agent's objective function is a unique feature of the regulatory application. In the economic literature, PAT usually takes the agent's objective function as given (See: Laffont \& Martimort 2002).

${ }^{35}$ See the discussion in Thaler \& Shefrin (1981), which bears directly on this claim, but without speaking of government.

${ }^{36}$ As a practical matter, complete delegation and incentive delegation often work differently, even in a rational choice framework. Incentive delegation is associated with lower prices and thus harnesses decentralized information, whereas complete delegation is associated with larger sanctions and thus imposes a one-size-fits-all outcome.

${ }^{37}$ Taxes need not be perceived as losses; rather they may be perceived as reducing the gain from a certain activity. Similarly, subsidies need not be perceived as gains; rather they may be perceived as reducing the loss from a certain activity. The identification of the reference point, against which losses or gains are measured, is critical (See Kahneman \& Tversky 1979; Zamir 2014).

${ }^{38}$ Or both, e.g., opt-out of no liability insurance default entails both extra insurance (gain) and a higher premium (loss).

${ }^{39}$ Compare Barr, Mullainathan, \& Shafir $(2008,2009)$ who propose to impose an enhanced disclosure requirement on sellers as a condition for opting consumers out of a pro-consumer regulatory default.

${ }^{40}$ For a related account of delegation from government agencies to regulated firms, see Bamberger (2006).

${ }^{41}$ But see Hale (1923) and Fried (2002), for some necessary qualifications.

${ }^{42}$ In the important context of fuel economy, see Bubb \& Pildes 2014.

${ }^{43}$ On the potential role of social norms in this context, see the discussion in Ellickson (1994) (showing that norms can solve public good problems); Ostrom (1990) (same). For an early and still valuable treatment, 
see Ulmann-Margalit (1976). Under certain conditions, social norms can justify a full delegation from government, if it knows that such norms will solve public goods problems.

${ }^{44}$ Note that the Affordable Care Act takes this approach insofar as it requires calorie labeling at chain $\begin{array}{llll}\text { restaurants } & \text { and } & \text { the }\end{array}$ http://www.fda.gov/Food/IngredientsPackagingLabeling/LabelingNutrition/ucm248732.htm

45 See IRS, Home Mortgage Interest Deduction, Publication $936 \quad$ (2014) (http://www.irs.gov/publications/p936/ar02.html) (incentive delegation); CFPB, Know Before You Owe (http://www.consumerfinance.gov/knowbeforeyouowe/ (information delegation); Barr, Mullainathan, \& Shafir, (2008) (veto-based delegation). 